\title{
Waste Derived Sorbents and Their Potential Roles in Heavy Metal Remediation Applications
}

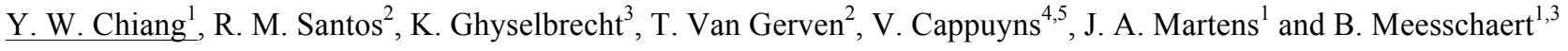 \\ ${ }^{1}$ Department of Microbial and Molecular Systems, Katholieke Universiteit Leuven, 3001 Heverlee, Belgium, \\ yiwai.chiang@biw.kuleuven.be,johan.martens@biw.kuleuven.be \\ ${ }^{2}$ Department of Chemical Engineering, Katholieke Universiteit Leuven, 3001 Heverlee, Belgium, \\ rafael.santos@cit.kuleuven.be, thomas.VanGerven@cit.kuleuven.be \\ ${ }^{3}$ Faculty of Industrial Engineering Sciences and Technology, Katholieke Hogeschool Brugge-Oostende, 8400 Oostende, \\ Belgium, karel.ghyselbrecht@khbo.be, boudewijn.meesschaert@biw.kuleuven.be \\ ${ }^{4}$ Department of Earth and Environmental Sciences, Katholieke Universiteit Leuven, 3001 Heverlee, Belgium \\ ${ }^{5}$ Faculty of Economics and Management, Hogeschool-Universiteit Brussel, Warmoesberg 26, B-1000 Brussels, Belgium, \\ valerie.cappuyns@hubrussel.be
}

\begin{abstract}
Inorganic waste materials that have the suitable inherent characteristics could be used as precursors for the synthesis of micro- and mesoporous materials, which present great potential to be re-utilized as sorbent materials for heavy metal remediation. Three inorganic waste materials were studied in the present work: water treatment residuals (WTRs) from an integrated drinking water/wastewater treatment plant, and fly ash and bottom ash samples from a municipal solid waste incinerator (MSWI). These wastes were converted into three sorbent materials: ferrihydrite-like materials derived from drying of WTRs, hydroxyapatite-like material derived from ultrasound assisted synthesis of MSWI fly ash with phosphoric acid solution, and a zeolitic material derived from alkaline hydrothermal conversion of MSWI bottom ash. The performance of these materials, as well as their equivalent commercially available counterparts, was assessed for the adsorption of multiple heavy metals ( $\mathrm{As}, \mathrm{Cd}, \mathrm{Co}, \mathrm{Ni}, \mathrm{Pb}, \mathrm{Zn}$ ) from synthetic solutions, contaminated sediments and surface waters; and satisfactory results were obtained. In addition, it was observed that the combination of sorbents into sorbent mixtures enhanced the performance levels and, where applicable, stabilized inherently mobile contaminants from the waste derived sorbents.
\end{abstract}

Key words: Heavy metals, waste derived sorbents, hydroxyapatite, zeolite, ferric hydroxide, remediation.

\section{Introduction}

Rising prices of raw materials and growing awareness for environmental issues have led to a change in perception of the value of waste materials. Waste recycling and re-utilization are potentially favorable routes towards development of environment-friendly, sustainable and cost effective industrial processes. Therefore, it is of great interest to explore the possibilities of turning wastes into valuable products. The use of modified waste materials as sorbents has attracted much attention (Bac et al., 2010, Chiang et al., 2011), given their large specific surface area, high sorption capacity and good cation exchange capability that help to adsorb heavy metals from aqueous media (Dimović et al., 2009). Potential applications of these sorbents include direct treatment of heavy metal laden streams (e.g. wastewater, groundwater, soil, and sediments) (Lin et al., 1998; Shevade and Ford, 2004; Ruggieri et al., 2008, Chiang et al., 2012).

In aquatic environment, heavy metals are usually distributed as follows: water-soluble species, colloids, suspended forms and sedimentary phases. However, unlike organic pollutants, natural processes of decomposition do not remove heavy metals. On the contrary, they become enriched in the sediment by organisms or some other compounds. In some conditions, more than $99 \%$ of heavy metals entering into river can be stored in river sediments in various forms (Qiu and Zheng, 2009). However, heavy metals cannot be fixed in sediment forever. With the variation of the physical-chemical characteristics of water conditions, part of these fixed metals will re-enter the overlying 
water and become available to living organisms. Thus, sediments often act as both carriers and potential sources for metals in an aquatic environment (Panuccio et al., 2009). Heavy metals usually possess significant toxicity to aquatic organisms, and eventually affect human health through the food chain. Therefore, investigating the transformation and distribution mechanisms of heavy metal in sediments becomes necessary.

Three chemicals have demonstrated high efficacy as sorbent materials for heavy metals: iron(hydro)oxides, hydroxyapatite, and zeolites.

Iron (hydro)oxides are known to play an important role in environmental remediation. Their large surface area, strong adsorptive properties, high adsorptive capacities and low cost make them attractive materials for contaminant removal by co-precipitation and adsorption. A range of metals can be adsorbed onto the sorbents by formation of inner-sphere sorption complexes or co-precipitation, as verified for $\mathrm{Cr}$, As, Se, $\mathrm{Cd}, \mathrm{Zn}, \mathrm{Cu}$ and $\mathrm{Pb}$ (Qian et al., 2009). Drinking water treatment residues (WTRs) are primarily amorphous masses of iron $(\mathrm{Fe})$ and aluminum (Al) hydroxides that are chemically similar to iron (hydro)oxides. WTRs are produced in large quantities in drinking-water treatment plants and are typically disposed of in landfills (Sarkar et al., 2007). Literature to date has focused on utilization of the waste by-product as a cost-effective sorbents for contaminants, such as arsenic (As), chromium (Cr) and phosphorus (P).

Hydroxyapatite (HAP, $\left.\mathrm{Ca}_{10}\left(\mathrm{PO}_{4}\right)_{6}(\mathrm{OH})_{2}\right)$ is commonly selected as an ideal amendment for sediment remediation. Generally, it is formulated in the form of calcium phosphate. In heavy metal remediation processes, metals firstly incorporate into the apatite lattice through ion exchange with $\mathrm{Ca}^{2+}$. This reaction can stimulate apatite dissolution and phosphate is released correspondingly. Due to the lower solubility between metal ions and phosphates, a new metal-phosphate solid phase consequently forms. Through these fixing processes, apatite minerals can effectively immobilize $\mathrm{Pb}$, $\mathrm{Mn}, \mathrm{Co}, \mathrm{Cu}, \mathrm{Cd}, \mathrm{Zn}, \mathrm{Mg}, \mathrm{Ba}, \mathrm{U}$, and $\mathrm{Th}$ in sediment (Peng et al., 2009). MSWI fly ash contains a high level of $\mathrm{Ca}$ in the form of free lime, and is intrinsically alkaline. These characteristics are ideal for synthesis of hydroxyapatite with addition of phosphoric acid solution.

Zeolites are crystalline aluminium-silicates, with many voids and open spaces for adsorption and entrapment of molecules in the internal channels. Synthesizing zeolite or zeolite-like material from thermal wastes has been regarded as an attractive alternative for these wastes. In Europe, in particular, where incineration is the key treatment for municipal wastes, the urge to fully utilize the waste ashes and minimize landfill burden is paramount. Municipal solid waste incineration (MSWI) residues contain oxides of silicon and aluminium, and have intrinsic basicity (Van Gerven et al., 2005). They are suitable for the synthesis of zeolitic substances that could be used as sorbents (Penilla et al., 2006; Bac et al., 2010). The incentives to use the waste-to-product valorization concept for the industry are to minimize the production and disposal costs. Synthetic zeolites have large specific surface area, high adsorption capacity and good cation exchange capability that help to reduce heavy metal concentration in aqueous media (Dimović et al., 2009).

\section{Materials and Methods}

Three waste materials were obtained from industries in Belgium: water treatment residuals (WTRs) from an integrated drinking water/wastewater treatment plant, and fly ash and bottom ash samples from a municipal solid waste incinerator (MSWI) in Flanders, Belgium, produced from a moving-grate furnace. Three types of waste derived sorbents were prepared: ferrihydrite-like materials derived from drying of WTRs, hydroxyapatite-like material derived from ultrasound assisted synthesis of MSWI fly ash with phosphoric acid solution, and a zeolitic material derived from alkaline hydrothermal conversion of MSWI bottom ash. Commercially available related materials (goethite, HAP and clinoptilolite natural zeolite) were also acquired for comparison of heavy metal adsorption performance.

Solid analysis was performed with X-ray diffraction (XRD) on a Philips PW1830 diffractometer for mineralogical analysis; X-ray Fluorescence (XRF) on Panalytical PW2400 was performed to obtain the chemical composition; and a Micromeritics TriStar 3000 was used to determine BET nitrogen adsorption-desorption isotherms.

The sorption capacity of the sorbents was tested by batch adsortion tests using synthetic single and multiple heavy metal solution at fixed $\mathrm{pH}$. The remediation performance of the sorbents towards the stabilization of multiple heavy metal contaminated sediments, obtained from brooks in the Campine region of Belgium, was assessed by batch adsorption tests. The remediation performance of the sorbents towards the treatment of multiple heavy metal contaminated surface waters from the same brooks was assessed by column adsorption tests. Aqueous samples were analyzed by Inductively Coupled Plasma Mass Spectrometry (ICP-MS) (Thermo Electron $\mathrm{X}$ Series) for determination of the equilibrium concentration of heavy metals in solution.

\section{Results and Discussion}

Figure 1 shows the crystallographic composition of the three waste derived sorbents determined by XRD. The modified MSWI fly ash contains primarily the diffraction peaks associated with HAP; many of the original mineral phases of the material, such as calcite and portlandite, nearly disappear, indicating high synthesis conversion. Two zeolitic phases are identified in the diffractogram of the modified MSWI bottom ash material: SASH (sodium aluminum silicate hydrate) and tobermorite. The modified WTRs were found to be highly amorphous, which is commensurate to its expected ferrihydrite content. 


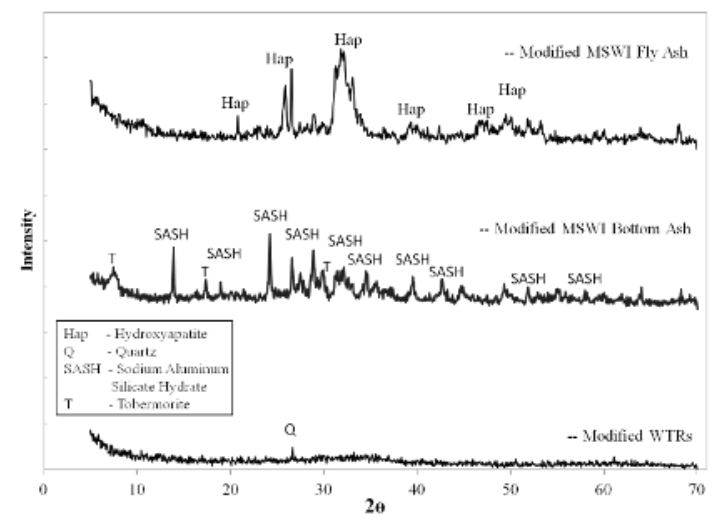

Figure 1. Crystallographic composition determined by X-ray Diffraction (XRD).

Figure 2 displays adsorption-desorption isotherms determined by nitrogen adsorption of the waste derived sorbents. Table 1 provides the specific surface areas of the materials determined by the BET method. The modified WTRs contained the greatest quantities of micro-pores, as indicated by the large nitrogen adsorption capacity at $\mathrm{P} / \mathrm{P}_{\mathrm{o}}<0.1$ and its high $\mathrm{BET}$ surface area $\left(96.2 \mathrm{~m}^{2} / \mathrm{g}\right)$, and meso-pores, as indicated by the slope in the interval $0.1-0.4$. The modified MSWI fly ash, in turn, possessed the greatest amount of macro-pores, as evidenced by the large hysteresis loop at $\mathrm{P} / \mathrm{P}_{\mathrm{o}}>0.4$, but it also presented a large specific surface area $\left(58.4 \mathrm{~m}^{2} / \mathrm{g}\right)$. The modified bottom ash delivered reduced nitrogen adsorption and a correspondingly smaller specific surface area $\left(22.1 \mathrm{~m}^{2} / \mathrm{g}\right)$.

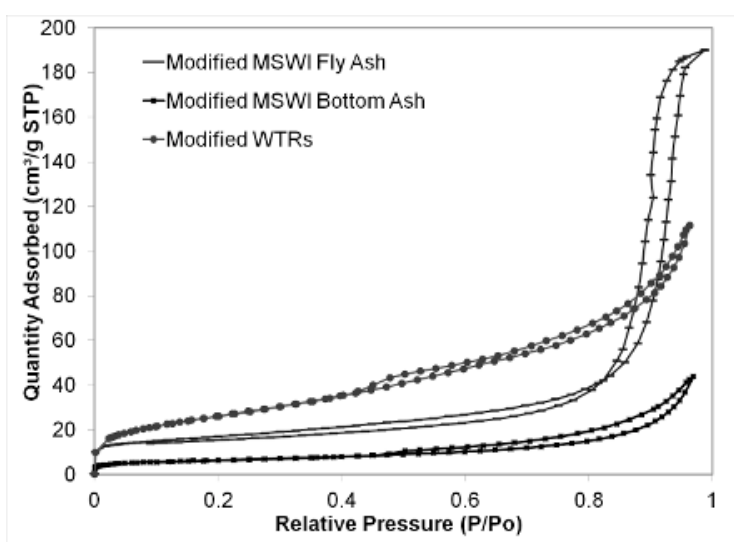

Figure 2. Nitrogen adsorption-desorption isotherms.

Table 1. Calculated BET surface areas

\begin{tabular}{lc}
\hline & $\begin{array}{c}\text { Surface Area } \\
\left(\mathrm{m}^{2} / \mathrm{g}\right)\end{array}$ \\
\hline Modified WTRs & 96.2 \\
Modified MSWI Fly Ash & 58.4 \\
Modified MSWI Bottom & 22.1 \\
Ash & \\
\hline
\end{tabular}

The remediation performance of the waste derived sorbents and their related commercially available materials towards multiple heavy metal contaminated sediments and surface waters was assessed by extensive experimentation work (in part in Chiang et al. (2011) and Chiang et al. (2012)). In cases where the performance of a single sorbent was not sufficient to provide the desired contaminant removal/stabilization, sorbent mixtures were composed using an in-house development methodology for sorbent mixture composition and dosage optimization (Chiang et al., 2012). Figure 3 provides the performance of a mixture of WTRs with natural zeolite towards the removal of zinc and cadmium from the porewater of contaminated sediments. Greater than $95 \%$ removal is achieved for the three sediment samples with varying contaminant concentrations and natural $\mathrm{pH}$ 's.
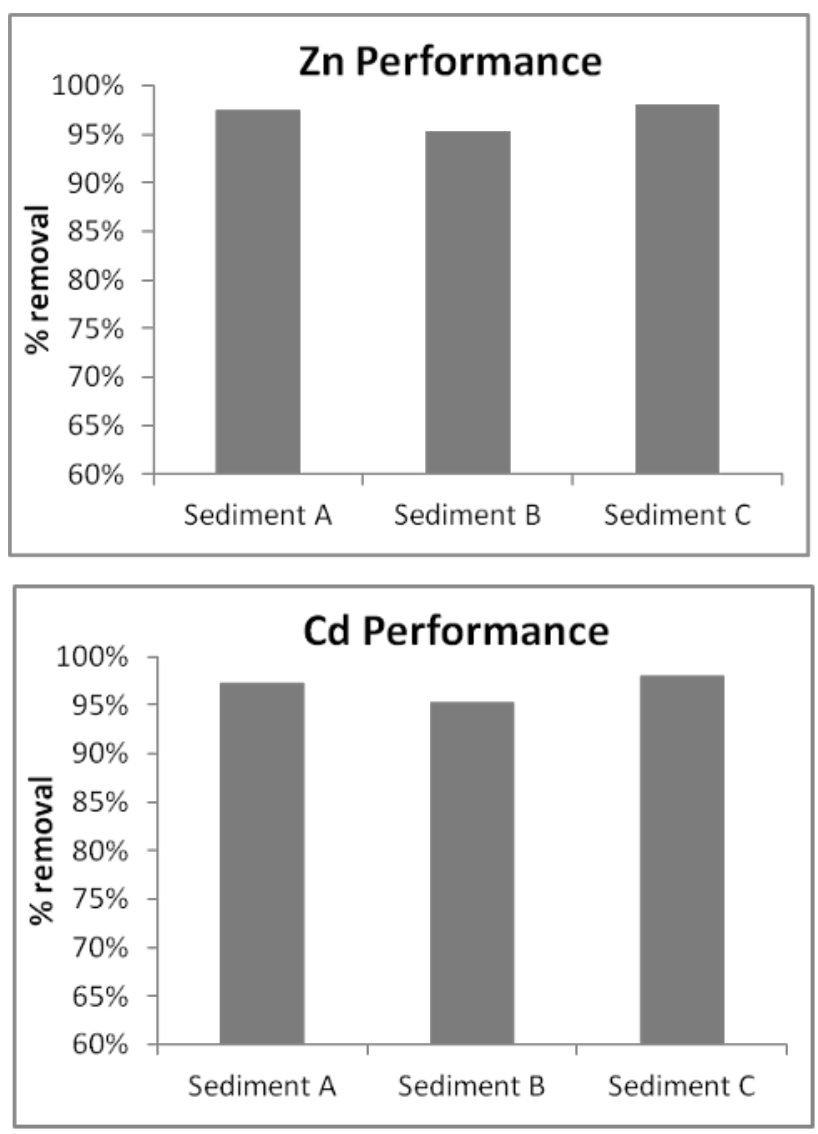

Figure 3. $\mathrm{Zn}$ and $\mathrm{Cd}$ removal by a sorbent mixture of WTRs and a natural zeolite on three different contaminated sediments.

\section{Conclusion}

Waste derived sorbents have been found useful in the remediation of multiple heavy metal contaminated sediments and surface waters. Their inherent toxicity, due to the production processes (e.g. incineration), can be stabilized during sorbent synthesis processes (e.g. alkaline hydrothermal conversion), therefore making them suitable for applications in the open environment. The approach of combining these sorbents into sorbent mixtures further enhances the efficacy and the versatility in their applications.

\section{Acknowledgements}

The K.U. Leuven Industrial Research Fund (IOF) is 
gratefully acknowledged for funding the Knowledge Platform on Sustainable Materialization of Residues from Thermal Processes into Products $\left(\mathrm{SMaRT}-\mathrm{Pro}^{2}\right)$ in which this work was performed.

\section{References}

Bac BH, Song Y, Moon Y, Kim MH, Kang IM. Effective utilization of incinerated municipal solid waste incineration ash: zeolitic material synthesis and silica extraction. Waste Manage Res 2010; 28:714-722.

Chiang YW, Ghyselbrecht K, Santos RM, Meesschaert B, Martens JA. Synthesis of zeolitic-type adsorbent material from municipal solid waste incinerator bottom ash and its application in heavy metal adsorption. Catal Today 2011; doi:10.1016/j.cattod.2011.11.002.

Chiang YW, Santos RM, Ghyselbrecht K, Cappuyns V, Martens JA, Swennen R, Van Gerven T, Meesschaert B. Strategic selection of an optimal sorbent mixture for in-situ remediation of heavy metal contaminated sediments: framework and case study. J Environ Manage 2012; doi:10.1016/j.jenvman.2012.03.037.

Dimović S, Smičiklas I, Plećaš I, Antonović D, Mitrić M. Comparative study of differently treated animal bones for $\mathrm{Co}^{2+}$ removal. J Hazard Mater 2009; 164:279-287.

Lin C-F, Lo S-S, Lin H-Y, Lee Y. Stabilization of cadmium contaminated soils using synthesized zeolite. J Hazard Mater 1998;60:217-226.
Panuccio MR, Sorgonà A, Rizzo M, Cacco G. Cadmium adsorption on vermiculite, zeolite and pumice: Batch experimental studies. J Environ Manage 2009;90:364-374.

Peng JF, Song YH, Yuan P, Cui X-Y, Qiu G-L. The remediation of heavy metals contaminated sediment. J Hazard Mater 2009;161:633-640.

Penilla RP, Bustos AG, Elizalde SG. Immobilization of $\mathrm{Cs}, \mathrm{Cd}, \mathrm{Pb}$ and $\mathrm{Cr}$ by synthetic zeolites from Spanish low-calcium coal fly ash. Fuel 2006;85:823-832.

Qian G, Chen W, Lim TT, Chui P. In-situ stabilization of $\mathrm{Pb}, \mathrm{Zn}, \mathrm{Cu}, \mathrm{Cd}$ and $\mathrm{Ni}$ in the multi-contaminated sediments with ferrihydrite and apatite composite additives. J Hazard Mater 2009;170:1093-1100.

Ruggieri F, Marín V, Gimeno D, Fernandez-Turiel JL, García-Valles M, Gutierrez L. Application of zeolitic volcanic rocks for arsenic removal from water. Eng Geol 2008;101:245-250.

Sarkar D, Makris KC, Datta R. Current trends and future directions in environmental geochemistry research, in: Sarkar, D., Datta, R., Hannigan, R. (Eds.), Developments in Environmental Science, Volume 5, 2007 Elsevier Ltd, pp. 753-757.

Shevade S, Ford RG. Use of synthetic zeolites for arsenate removal from pollutant water. Water Res 2004;38:3197-3204.

Van Gerven T, Van Keer E, Arickx S, Jaspers M, Wauters G, Vandecasteele C. Carbonation of MSWI-bottom ash to decrease heavy metal leaching, in view of recycling. Waste Manage. 2005;25:291-300. 